\title{
A case of gastrointestinal hemorrhage during aspirin therapy in a patient with Kawasaki disease
}

\author{
Yo-Eon Shin, Yong Wook Kim, Kyoung Sim Kim, Eun Young Kim, Young Kim, Hae In Jang, \\ Hyoung Min Cho
}

Department of Pediatrics, Kwangju Christian Hospital, Gwangju, Korea

Received September 21, 2020

Revised October 26, 2020

Accepted October 27, 2020

Corresponding author

Hyoung Min Cho

Department of Pediatrics, Kwangju

Christian Hospital, 37 Yangnim-ro,

Nam-gu, Gwangju 61661, Korea

Tel: +82-62-650-5045

Fax: +82-62-650-5040

E-mail: drcho92@hanmail.net

ORCID:

https://orcid.org/0000-0003-1263-5292
Kawasaki disease (KD) is an acute febrile multisystem vasculitis and has been recognized to be one of the most common causes of acquired heart disease in children. KD with gastrointestinal bleeding is quite rare. We report a 12-month-old boy with KD complicated by gastrointestinal hemorrhage after using of high-dose of aspirin. Physicians caring for patients with KD should mindful on the signs and symptoms of aspirin toxicity including gastrointestinal hemorrhage. Starting or early switching to a low-dose aspirin treatment on KD should be considered.

Keywords: Kawasaki disease; Gastrointestinal hemorrhage; Aspirin; Ulcer

\section{INTRODUCTION}

Kawasaki disease, formerly called mucocutaneous lymph node syndrome, is one of the most common vasculitis of childhood. Intravenous immunoglobulin (IVIG) and aspirin have been considered as the standard initial treatment of $\mathrm{KD}$ for decades [1,2]. Although gastrointestinal hemorrhage is a well-recognized complication of aspirin therapy, it has been previously reported in only a few patients with $\mathrm{KD}$ [36. We describe a patient with typical $\mathrm{KD}$ who had massive gastrointestinal bleeding that required hospitalization and transfusion.

\section{CASE REPORT}

A previously healthy, 12-month-old boy was hospitalized with 3 days of typical signs of $\mathrm{KD}$; fever, bilateral non-exudative conjunctivitis, erythema of the lips and oral mucosa, body rash and neck swelling. Initial laboratory tests showed a hemoglobin concentration of $10.1 \mathrm{~g} / \mathrm{dL}$, white blood cell count of $21,200 / \mathrm{mm}^{3}$, platelet count of 423,000 cells $/ \mu \mathrm{L}$, Erythrocyte sedimentation rate of $72 \mathrm{~mm} / \mathrm{hr}$, and C-reactive protein level of $9.1 \mathrm{mg} / \mathrm{dL}$.

On the second day of admission, high-dose aspirin therapy $(100 \mathrm{mg} / \mathrm{kg} /$ day $)$ was started. however, $\mathrm{KD}$ symptoms persisted. On day 3, IVIG administration ( $2 \mathrm{~g} / \mathrm{kg} /$ day) was started. After IVIG administration, fever persisted for more 
than 36 hours, and a second regimen of IVIG was administered on day 5. On the same day, the patient looked pale and showed decreased consciousness. Vital signs were as follows; blood pressure was 70/40 $\mathrm{mmHg}$; heart rate was 170 beats per minute; respiratory rate was 60 breaths per minute, and saturation on room air was $90 \%$. Laboratory tests showed a hemoglobin concentration of $2.5 \mathrm{mg} / \mathrm{dL}$, platelet count of 257,000 cells/ $\mu \mathrm{L}$, alanine aminotransferase of $27 \mathrm{u} / \mathrm{L}$, aspartate aminotransferase of $21 \mathrm{u} / \mathrm{L}$, prothrombin time of 22.2 seconds (INR 2.04), and partial thromboplastin time of 58.8 seconds, antithrombin III 57\%, D-dimer $20.9 \mathrm{ug} / \mathrm{mL}$. We diagnosed hypovolemic shock with disseminated intravascular coagulation. He received massive blood transfusion and was transferred to the pediatric intensive care unit. We performed computed tomography (CT) scans of the brain and gastrointestinal tract to find the bleeding site. A hematoma in the stomach was observed on abdom- inal CT (Fig. 1). A large amount of blood clot was observed through the nasogastric tube, and melena was observed on the next day. A diagnosis of upper gastrointestinal bleeding was made. Esophagogastroduodenoscopy (EGD) could not be performed immediately because of the patient's unstable vital signs. We stopped high-dose aspirin therapy and administered high-dose proton pump inhibitor and octreotide. On day 9, his hemoglobin level $(11.2 \mathrm{~g} / \mathrm{L})$ and blood pressure (90/60 mmHg) normalized. Echocardiography performed on days 3,7,11 and 21 showed no abnormalities. EGD performed on day 22 showed a healing ulcer on the bulb of the duodenum (Fig. 2A). After maintaining proton pump inhibitor therapy for six weeks, the disappearance of the ulcer was confirmed by follow-up EGD (Fig. 2B). The patient was followed up with an echocardiography in the outpatient clinic without aspirin treatment, and there was no coronary artery (CA) complication.
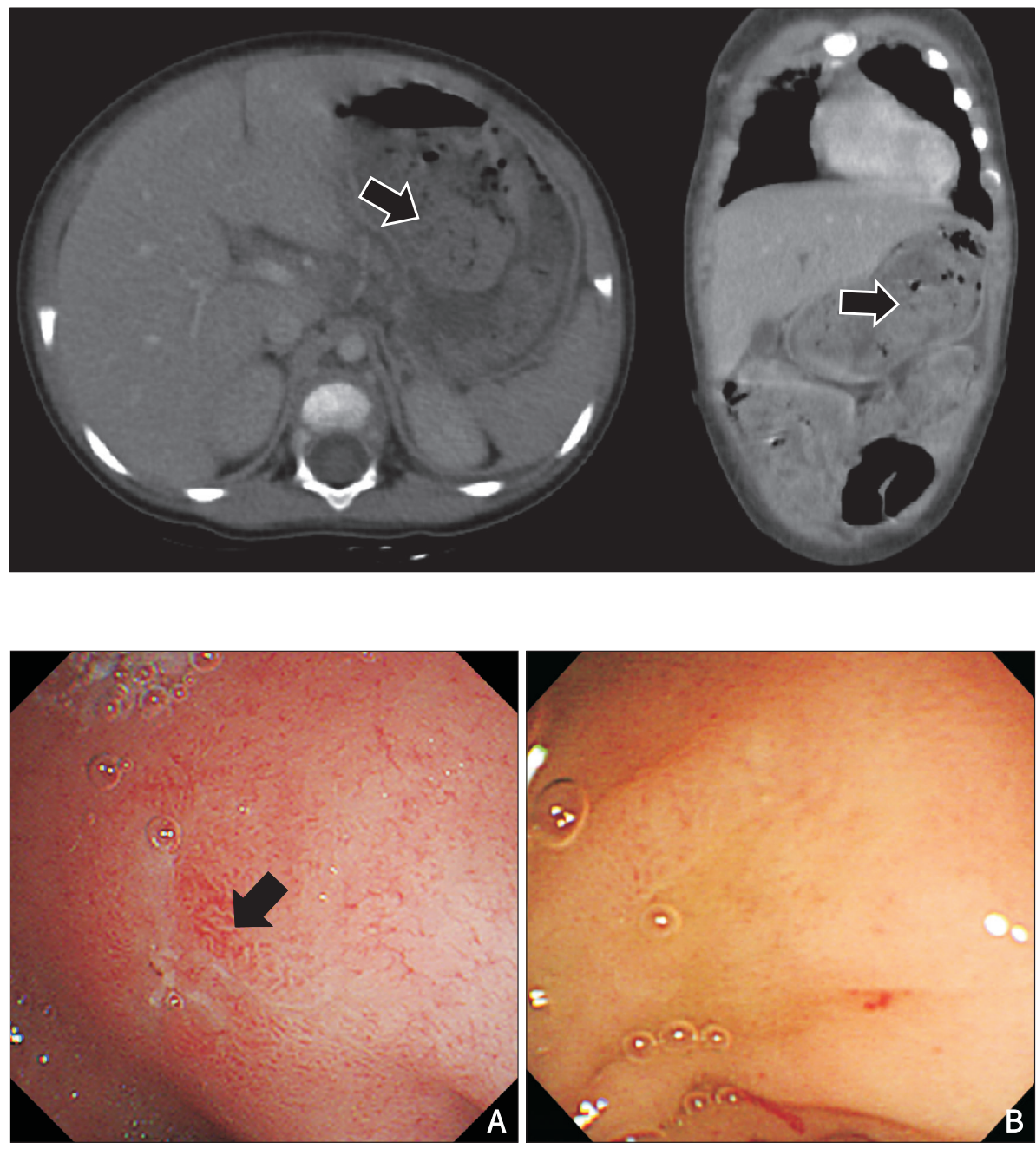

Fig. 2. EGD findings: (A) on day 22, showing a healing ulcer (arrow) on the bulb of duodenum. (B) Follow-up EGD (two months later) findings show the healing ulcer has disappeared. 


\section{DISCUSSION}

$\mathrm{KD}$ is a systemic, idiopathic vasculitis that occurs predominantly in infants and children younger than 5 years. $[1,2,7]$ The most significant complication is coronary artery abnormalities (CAA) including aneurysms which occurs in 20-25\% of untreated children [2,7].

Over decades, IVIG and aspirin have been considered the standard initial treatment of KD. The incidence of CAA on morbidity and mortality have dramatically decreased as a result of IVIG treatment. Aspirin was one of the first treatments used for KD because of its anti-inflammatory and antiplatelet effects [7]. But the role and appropriate dose of aspirin is still unclear during the acute phase of illness [8]. Moreover, it is not certain that the IVIG combined with aspirin provides greater anti-inflammatory effects than IVIG alone. Several meta-analyses have shown that aspirin does not affect aneurysm formation $[9,10]$. The dose of aspirin needed to achieve anti-inflammatory effects during the acute phase of illness is relatively high, with a recommended range of $30-100 \mathrm{mg} / \mathrm{kg}$ per day in four divided doses. In North America, high-dose ( $80-100 \mathrm{mg} / \mathrm{kg}$ per day) aspirin is most widely used during the acute phase. In Japan, concern about hepatic toxicity have led to the use of moderate dose (30-50 $\mathrm{mg} / \mathrm{kg}$ per day) aspirin as a recommended standard therapy in the acute phase $[1,11,12]$.

The risks of aspirin therapy are low and appear to be sim- ilar to those reported in other settings, including chemical hepatitis with elevated transaminases, transient hearing loss, dose-related hemolytic anemia [13], and rarely, Reye syndrome. Gastrointestinal hemorrhage is reported in patients administered high-dose aspirin after being diagnosed with KD [3,5]. We describe each cases: a 2-year-old boy diagnosed with $\mathrm{KD}$ took aspirin $(71 \mathrm{mg} / \mathrm{kg} /$ day $)$ during the acute phase and experienced acute gastrointestinal bleeding after 13 days of aspirin treatment. EGD revealed an ulcer $(2 \mathrm{~cm}$ in size) in the duodenum [3]. A 4-year-old girl who took aspirin $(100 \mathrm{mg} / \mathrm{kg} /$ day $)$ experienced melena followed by emesis of blood on day 26 of aspirin treatment. She did not have an endoscope [3]. A 5-year-old boy had tarry stool on day 6 of fever without taking aspirin. But three days later, he was treated with aspirin $(80 \mathrm{mg} / \mathrm{kg} /$ day) and massive GI bleeding occurred on day 5 of aspirin treatment [4]. A 3-year-old boy who took aspirin $(50 \mathrm{mg} / \mathrm{kg} /$ day) experienced hematochezia on the third day after taking aspirin. Multiple rectal superficial ulcers were observed in colonoscopy [5]. The cases are summarized in Table 1 . All cases were patients who took doses of aspirin higher than $50 \mathrm{mg} / \mathrm{kg} /$ day. Our case took aspirin at a dose of $100 \mathrm{mg} / \mathrm{kg} /$ day.

Aspirin can cause GI mucosal damage from prostaglandin depletion via inhibition of cyclooxygenase-1. Prostaglandins play a pivotal role in protecting gastric mucosal integrity via increasing local blood flow and promoting the synthesis and secretion of mucus and bicarbonate. In the absence of

Table 1. Clinical characteristics of the patients with gastrointestinal hemorrhage in Kawasaki disease

\begin{tabular}{|c|c|c|c|c|c|c|c|}
\hline Case & & Age & Sex & Details of gastrointestinal bleeding & Transfusion & Endoscopy & Aspirin dose \\
\hline \multirow[t]{2}{*}{ Matsubara et al. } & 1 & $2 y$ & M & $\begin{array}{l}\text { Hematemesis on day } 19 \\
\text { (day } 13 \text { of aspirin) }\end{array}$ & Yes & $2 \mathrm{~cm}$ sized duodenal ulcer & $\begin{array}{c}(+) \\
71 \mathrm{mg} / \mathrm{kg} / \mathrm{d}\end{array}$ \\
\hline & 2 & $4 y$ & $\mathrm{~F}$ & $\begin{array}{l}\text { Melena followed by emesis of blood on day } \\
31 \text { (day } 26 \text { of aspirin) }\end{array}$ & Yes & None & $\begin{array}{c}(+) \\
100 \mathrm{mg} / \mathrm{kg} / \mathrm{d}\end{array}$ \\
\hline Chang et al. & 3 & $5 y$ & M & $\begin{array}{l}\text { Tarry stool on day } 6 \text { (without aspirin) } \\
\text { Massive GI bleeding on day } 14 \text { (day } 5 \text { of } \\
\text { aspirin) }\end{array}$ & Yes & Not available & $\begin{array}{c}(+) \\
80 \mathrm{mg} / \mathrm{kg} / \mathrm{d}\end{array}$ \\
\hline Han et al. & 4 & $3 y$ & M & Hematochezia (day 3 of aspirin) & No & $\begin{array}{l}\text { Multiple superficial ulcers in } \\
\text { rectum }\end{array}$ & $\begin{array}{c}(+) \\
50 \mathrm{mg} / \mathrm{kg} / \mathrm{d}\end{array}$ \\
\hline Zulian et al. & 5 & 20 mon & M & Hematemesis on day 7 (without aspirin) & Yes & $\begin{array}{c}\text { Diffuse hemorrhagic } \\
\text { duodenitis }\end{array}$ & $(-)$ \\
\hline Singh et al. & 6 & $4 y$ & M & $\begin{array}{l}\text { Hemorrhagic shock with hematemesis and } \\
\text { hematochezia at } 2 \text { months after onset } \\
\text { (without aspirin) }\end{array}$ & Yes & $\begin{array}{l}\text { Failed } \mathrm{d} / \mathrm{t} \text { massive bleeding } \\
\text { done surgery }(1.5 \mathrm{~cm} \text { sized } \\
\text { duodenal ulcer })\end{array}$ & $(-)$ \\
\hline Sohn et al. & 7 & $3 y$ & M & Hematemesis (without aspirin) & No & Gastroduodenal ulcer & $(-)$ \\
\hline Hu et al. & 8 & $4 y$ & M & $\begin{array}{l}\text { Vomit coffee-like liquid, tarry stool on day } 5 \\
\text { (without aspirin) }\end{array}$ & No & Duodenal bulb ulcer & $(-)$ \\
\hline
\end{tabular}


normal prostaglandin synthesis, the gastric environment becomes more vulnerable to exogenous (i.e. smoking) or endogenous factors (i.e. H. pylori, acid, pepsin, and bile salts) and consequently, more prone to developing peptic ulcers and bleeding complications [14].

Gastrointestinal bleeding has been reported in patients with $\mathrm{KD}$ who did not use aspirin [6]. Without aspirin use, gastrointestinal bleeding may occur as a complication of $\mathrm{KD}$. The exact mechanism is not known, but it is speculated that vasculitis in the gastrointestinal tract or $\mathrm{KD}$-related stress may be the cause of bleeding in the gastrointestinal tract.

Gastrointestinal bleeding is rare in patients with $\mathrm{KD}[3,5$, 15]. However, attention should be paid to the occurrence of gastrointestinal bleeding. Many studies have reported that aspirin treatment does not reduce the incidence of coronary artery complications $[16,17]$. Several studies showed no significant difference between aspirin doses and IVIG resistance rates, CA lesion formation, duration of hospitalization [16-18].

In order to prevent gastrointestinal bleeding, we should consider that administer a dose of less than $50 \mathrm{mg} / \mathrm{kg} /$ day and switch to a low-dose of aspirin as soon as symptoms are improved. We can also consider starting with a low-dose aspirin from the beginning or PPI treatment for prophylaxis on $\mathrm{KD}$ during the acute phase.

Physicians caring for patients with $\mathrm{KD}$ should instruct parents on the signs and symptoms of aspirin toxicity including gastrointestinal hemorrhage and should always be mindful of the possibility of gastrointestinal bleeding that can occur when taking aspirin.

\section{CONFLICT OF INTEREST}

No potential conflict of interest relevant to this article was reported.

\section{REFERENCES}

1. Burns JC, Glodé MP. Kawasaki syndrome. Lancet 2004;364: 533-44.

2. Newburger JW, Takahashi M, Burns JC. Kawasaki disease. J Am Coll Cardiol 2016;67:1738-49.

3. Matsubara T, Mason W, Kashani IA, Kligerman M, Burns JC.
Gastrointestinal hemorrhage complicating aspirin therapy in acute Kawasaki disease. J Pediatr 1996;128:701-3.

4. Chang $\mathrm{CH}$, Chen $\mathrm{MH}$, Yang W. Kawasaki disease presenting with lymphadenopathy and gastrointestinal hemorrhage: report of one case. Acta Paediatr Taiwan 2004;45:171-3.

5. Han Y, Hu C, Yu Y. A case of rectal ulcers during aspirin therapy in acute Kawasaki disease. Pediatr Rheumatol Online J 2020;18:24.

6. Sohn H, Kim K, Koh H, Kim S. A case of gastroduodenal ulcer complicating Kawasaki disease. Pediatr Emerg Med J 2019;6:81-5.

7. McCrindle BW, Rowley AH, Newburger JW, Burns JC, Bolger AF, Gewitz M, et al. Diagnosis, treatment, and long-term management of Kawasaki disease: a scientific statement for health professionals from the American Heart Association. Circulation 2017;135:e927-99.

8. Saulsbury FT. Comparison of high-dose and low-dose aspirin plus intravenous immunoglobulin in the treatment of Kawasaki syndrome. Clin Pediatr (Phila) 2002;41:597-601.

9. Durongpisitkul K, Gururaj VJ, Park JM, Martin CF. The prevention of coronary artery aneurysm in Kawasaki disease: a meta-analysis on the efficacy of aspirin and immunoglobulin treatment. Pediatrics 1995;96:1057-61.

10. Terai M, Shulman ST. Prevalence of coronary artery abnormalities in Kawasaki disease is highly dependent on gamma globulin dose but independent of salicylate dose. J Pediatr 1997;131:888-93.

11. Newburger JW, Takahashi M, Gerber MA, Gewitz MH, Tani LY, Burns JC, et al. Diagnosis, treatment, and long-term management of Kawasaki disease: a statement for health professionals from the Committee on Rheumatic Fever, Endocarditis and Kawasaki Disease, Council on Cardiovascular Disease in the Young, American Heart Association. Circulation 2004;110:2747-71.

12. Giglia TM, Massicotte MP, Tweddell JS, Barst RJ, Bauman M, Erickson CC, et al. Prevention and treatment of thrombosis in pediatric and congenital heart disease: a scientific statement from the American Heart Association. Circulation 2013;128:2622-703.

13. Berard R, Whittemore B, Scuccimarri R. Hemolytic anemia following intravenous immunoglobulin therapy in patients treated for Kawasaki disease: a report of 4 cases. Pediatr Rheumatol Online J 2012;10:10.

14. Cryer B, Mahaffey KW. Gastrointestinal ulcers, role of aspirin, and clinical outcomes: pathobiology, diagnosis, and treatment. J Multidiscip Healthc 2014;7:137-46.

15. Hu C, Yu Y. Gastrointestinal hemorrhage before anticoagulant therapy in Kawasaki disease: a case report. BMC Pediatr 2020;20:32.

16. Ogata S, Tremoulet AH, Sato Y, Ueda K, Shimizu C, Sun X, 
et al. Coronary artery outcomes among children with Kawasaki disease in the United States and Japan. Int J Cardiol 2013;168:3825-8.

17. Kuo HC, Lo MH, Hsieh KS, Guo MM, Huang YH. Highdose aspirin is associated with anemia and does not confer benefit to disease outcomes in Kawasaki disease. PLoS One 2015;10:e0144603.

18. Platt B, Belarski E, Manaloor J, Ofner S, Carroll AE, John CC, et al. Comparison of risk of recrudescent fever in children with Kawasaki disease treated with intravenous immunoglobulin and low-dose vs high-dose aspirin. JAMA Netw Open 2020;3:e1918565. 